\title{
A conceptual vulnerability and risk framework as outline to identify capabilities of remote sensing
}

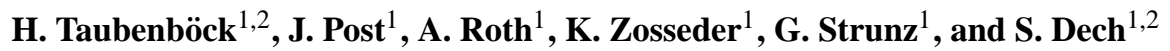 \\ ${ }^{1}$ German Remote Sensing Data Center (DFD), German Aerospace Center (DLR), 82234 Wessling, Germany \\ ${ }^{2}$ Julius-Maximilians-University Würzburg, Geographic Institute, Am Hubland, 97074 Würzburg, Germany
}

Received: 20 December 2007 - Revised: 26 February 2008 - Accepted: 23 April 2008 - Published: 6 May 2008

\begin{abstract}
This study aims at creating a holistic conceptual approach systematizing the interrelation of (natural) hazards, vulnerability and risk. A general hierarchical risk meta-framework presents potentially affected components of a given system, such as its physical, demographic, social, economic, political or ecological spheres, depending on the particular hazard. Based on this general meta-framework, measurable indicators are specified for the system "urban area" as an example. This framework is used as an outline to identify the capabilities of remote sensing to contribute to the assessment of risk. Various indicators contributing to the outline utilizing diverse remote sensing data and methods are presented. Examples such as built-up density, main infrastructure or population distribution identify the capabilities of remote sensing within the holistic perspective of the framework. It is shown how indexing enables a multilayer analysis of the complex and small-scale urban landscape to take different types of spatial indicators into account to simulate concurrence. The result is an assessment of the spatial distribution of risks within an urban area in the case of an earthquake and its secondary threats, using an inductive method. The results show the principal capabilities of remote sensing to contribute to the identification of physical and demographic aspects of vulnerability, as well as provide indicators for the spatial distribution of natural hazards. Aspects of social, economic or political indicators represent limitations of remote sensing for an assessment complying with the holistic risk framework.
\end{abstract}

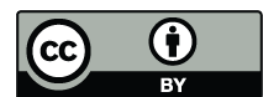

Correspondence to: $\mathrm{H}$. Taubenböck (hannes.taubenboeck@dlr.de)

\section{Introduction}

So far, the international community's response to disasters has been mostly reactive, with only limited budget invested in prevention. (...) Even if there were a willingness to invest in prevention, the question would be: where? (Peduzzi, 2006)

The main challenge within the field of disaster reduction is to change people's perception so that they can recognize this notion of disasters as the outcome of a development process whereby societies have implicitly generated vulnerabilities and risks which become evident during the disaster (Villagran de Leon, 2006). But, assessing vulnerability and risk to natural hazards such as earthquakes can be regarded as an ill-structured problem (i.e., a problem for which there is no unique, identifiable, objectively optimal solution) (Rashed et al., 2003). Conceptualizations of the various scientific communities are inconsistent, causing misunderstanding in a research field needing multidisciplinary approaches to cope with the holistic effects. Both humanities (Alwang et al., 2001; Blaikie et al., 1994; Briguglio, 1995; Cannon et al., 2003) and natural sciences (Chapman, 1994; Brooks, 2003; Turner et al., 2003) define the terms differently and concentrate on various focal points.

Vulnerability is a term of such broad use as to be almost useless for careful description at the present, except as a rhetorical indicator of areas of greatest concern (Timmermann, 1981)

On this subject Birkmann (2006a), for example, stresses the need for a paradigm shift from the quantification and analysis of the hazard to the identification, assessment and ranking of vulnerabilities. This study proposes a comprehensive and consistent conceptual risk framework using a hierarchical structure including the hazard and the vulnerability. The conceptual approach provides a general abstract metaframework applicable to any system, element at risk, scale

Published by Copernicus Publications on behalf of the European Geosciences Union. 
or time. The concept consistently systematizes the metaframework down to components highlighting various aspects of vulnerability and hazards resulting in a set of measurable indicators. Thus, risk assessment results from a multilayered analysis of individual indicators, in the ideal case representing the complete range of components contributing to hazards and vulnerability. With respect to the temporal risk cycle, the framework considers the stages of a potential disaster with time-dependent indicators.

In this study the proposed conceptual framework serves as an outline to identify capabilities and limitations of remote sensing - as one scientific community - to contribute values for indicators for the assessment of vulnerability and risk. For the example of an 'urban landscape prone to an earthquake threat' different remote sensing data and methods are used to derive precise values of indicators. Using high and medium resolution optical satellite data, as well as radar data, remote sensing products are presented which map the spatial distribution of the indicators in the outline. Especially physical indicators characterising the complex arrangement of urban objects are shown. Examples are the built-up density or the street network, which specify the spatial distribution and number of potentially affected houses or their accessibility and the ability to evacuate in case of an earthquake. In addition the derived physical urban structures - building area, building height, building density and land use - are used to calculate the population density distribution as a demographic indicator. Furthermore, a time series of Landsat data enables the computation of physical urbanization rates and the assessment of building ages. The digital elevation model from the Shuttle Radar Topography Mission (SRTM) is used to derive slope maps. The slope is one component used to assess the spatial distribution of the secondary threat "landslide", and the surface height information is used as an approximation for modelling potentially tsunami-prone areas.

Recapitulating the results, the conceptual framework presents a holistic perspective on hazards, vulnerability and risk. Using the system "urban area" and the earthquake threat, indicators specific to this example are listed to concretize the conceptual and generic meta-framework. This enables identification of the capabilities of remote sensing to contribute aspects of the holistic concept to support risk management, but also demonstrates the need for multidisciplinary approaches to satisfy the whole spectrum of the holistic idea. The structure of the study is two-fold: in the first part a general conceptual risk framework is developed and used as outline in the second part to identify contributions of remote sensing to this developed framework for the model case. In particular, this study aims to address several specific questions:

- How can risk, vulnerability and hazards be conceptualized in a general and transferable framework?

- What can remote sensing data and methods contribute toward assessing risk and vulnerability in their spatial distribution?

- How can the abstract terms in the framework be sampled to quantifiable indicators?

\section{Conceptual framework of hazards, vulnerability and risk}

Risk specifies something prospective and imaginary, and thus implies uncertainty. The effect of a natural hazard on the objects or people of a particular area exemplify the complex interrelationships and emerging domino effects. The UN (1991) and the UNDP (2004) define a conceptual superstructure as follows:

Risk $=$ Hazard $\times$ Vulnerability

Thus, risk results from a future interplay of a hazard and the various components defining vulnerability. The conceptual superstructure of risk shows an internal and an external side (Bohle, 2001): The internal side relates to the capacity to anticipate, cope with, resist and recover from the impact (vulnerability), and the external side specifies the type and intensity of the hazard. This conceptual meta-framework (1) describes the general correlation, but displays an abstract approach not reflecting the complex interrelations of both the components and their various aspects. This study aims at a conceptual holistic framework to systematize the abstract terms "hazard", "vulnerability" and "risk". A hierarchical systematization of the abstract terms results in quantifiable and thus measurable indicators:

The hazard component in equation 1 is defined as the probability of a disastrous event happening in a certain period of time, with a particular intensity at a particular location (Unesco, 1973). Examples for hazards are earthquakes, floods, droughts, tropical storms or volcanic eruptions, with some of them causing secondary threats such as landslides, fires or tsunamis. Depending on the nature of the hazard, indicators describing the hazard like intensity or duration specify the hazard event as well as the condition of the location, which is described by indicators like soil type, surface height or slope.

The second component in Eq. 1 is the term "vulnerability", which shows fuzziness in the interdisciplinary risk research community definitions. "We are still dealing with a paradox: we aim to measure vulnerability, yet we cannot define it precisely" (Birkmann, 2006a). Generally the conceptual idea of vulnerability is based on Eq. 2:

Vulnerability $=\frac{\text { Exposure } \times \text { Susceptibility }}{\text { CopingCapacity }}$ (White et al., 2005) (2)

Thus, vulnerability is the interrelation of the exposure and the susceptibility as stressor of the system with the coping capacity as the potential of the system to decrease the impact of the hazard. Exposure is defined as degree, duration 
and/or extent in which a system is in contact with, or subject to, perturbation (Adger, 2006; Kasperson et al., 2005). Susceptibility reflects the capacity of individuals, groups or the physical or socio-economic system to withstand the impact of the hazard. If resistance is low then even a small hazard can lead to system failure (Pelling, 2003). The coping capacity is the ability to cope with or adapt to hazard stress. It is the product of planned preparation, spontaneous adjustments and relief and reconstruction made in response to the hazard. For a comprehensive approach Füssel (2005) identifies four fundamental dimensions to consider for an assessment: 1) the system/region or population group of concern, 2) the type of hazard, 3) the valued attribute, which serve as indicators threatened by exposure to the hazard, 4) the temporal reference, specifying the period of interest for the assessment. For further general reviews of conceptualization approaches regarding vulnerability, the reader is referred to Livermann (1990); Cutter (1996); Kasperson and Kasperson (2001); Cardona 2003; Birkmann (2006b); Schneiderbauer and Ehrlich (2006); Schneiderbauer (2007) or Füssel (2007).

The disaster management cycle relates the conceptual idea of this study about vulnerability and risk to the timeline. The abstract terms of the conceptual idea are reflected in different stages of the disaster management cycle (Fig. 1). For example, coping capacity can be specified as preparedness before a disastrous event, existing intervention tools during an event, or capabilities to recover from the hazard stress after the event. The cycle highlights various temporal phases where different types of indicators enable assessment of the situation. For example, knowledge about accessibility and evacuation bottlenecks may lead to preventive measures. In addition, spatial information on the number and location of affected people enables coordination and management of reaction measures during and after the event. These actions aim to reduce risk before an event, to cope during, and react after the event.

Again, the abstract terms used in the meta-framework and Fig. 1 do not specify the complex and dynamic interdependencies of a myriad of different indicators contributing to the concept of vulnerability and risk in a measurable way. Therefore this study designs a hierarchical partition of the terms into thematic components establishing a relationship to various disciplines (Table 1). Following the definition of the UN/ISDR (2004) this study aims at a holistic perspective on vulnerability and defines it with direct regard to the conceptual framework as follows:

Subject to the considered period of time, the geographic location (system) and a scale-dependent reference system, vulnerability is defined as the condition determined by physical, demographic, social, economic, environmental and political factors or processes which increase the susceptibility of a community to the impact of hazards.

Components specifying vulnerability include the physical, demographic, social, economic, ecological and political aspects contributing and adding up to the holistic con-

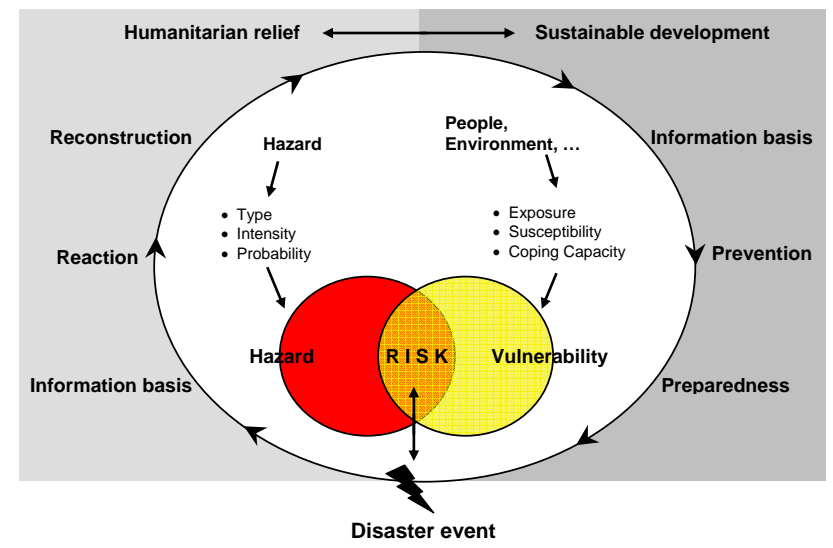

Fig. 1. Risk as result of the interaction of the hazard and the vulnerability embedded in the various phases of the disaster management cycle (modified; ADPC, 2003; DKKV, 2002; Schneiderbauer, 2007; WISNER, 2004).

ceptual idea (Table 1). This conceptual idea reflects a metaframework applicable to various systems (e.g., urban areas), various elements or attributes within a system (buildings, people, environmental services, etc.), various scales (local, regional, national, global), and various hazards (earthquake, climate change, etc.). In general the various components described above suggest the complexity of dynamic interactions and interdependencies evolving in a system in case of a disastrous event. This highlights the need for multidisciplinary scientific approaches to converge on the problem of holistic identification of vulnerability and risk.

To converge on the problem of assessing the complexity of risk and vulnerability, the rather abstract components of this meta-framework need further partitioning. Specifications are dependent on the considered system and the type of hazard. In our case, indicators are developed for the example of an "urban system prone to an earthquake hazard". A consistent systematization itemizes the components into a set of measurable indicators contributing to all the various stages of the risk management cycle. An indicator is defined as a variable which is a representation of an attribute, such as quality and/or characteristics of a system (Gallopin, 1997). The quality of the indicator is determined by its ability to indicate the characteristics of a system which are relevant to the underlying interest determined by the goal or guiding vision (Birkmann, 2006b).

The result is an arbitrary number of measurable indicators contributing aspects to the associated component and to the ranking in the holistic conceptual framework. Downing (2004) stresses the fact that indiscriminate use of indicators for measuring vulnerability must be avoided. The approach in this study aims at a detailed listing of potential indicators, in order to identify the capabilities of remote sensing at various scales, times or objects. Thus, Table 1 presents a selection of specific indicators describing the many kinds of 
Table 1. A hierarchical holistic framework conceptualizing hazards, vulnerability and risk to derive a selection of measurable indicators for a specified system.

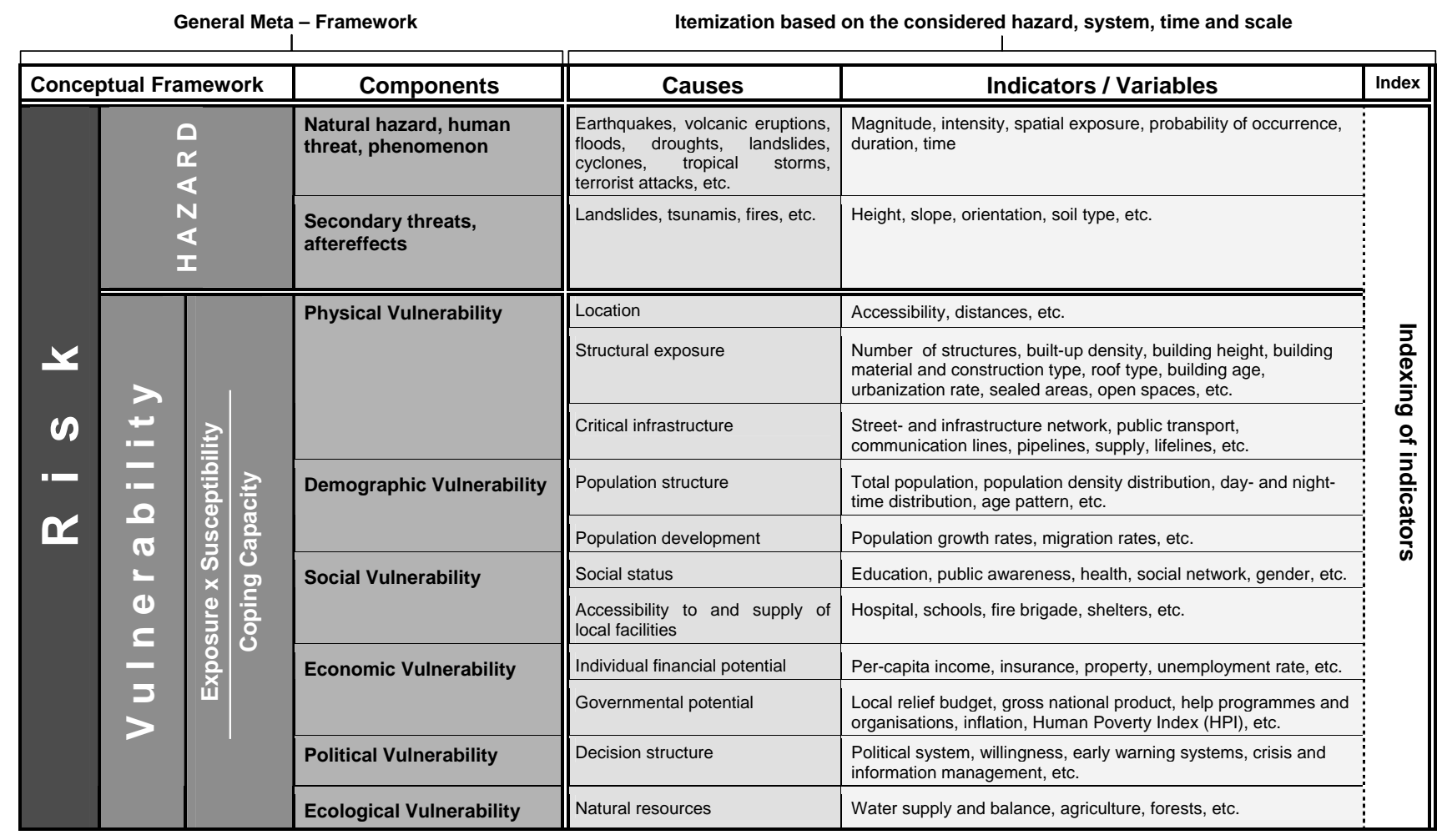

vulnerability and risks at different scales and points of time. The example in this study specifies the four fundamental dimensions (Füssel, 2005) such as an urban landscape, prone to an earthquake, causing secondary threats, like tsunamis and landslides. The valued attributes are the components defined above using as temporal reference for the assessment the forefront of a disastrous event. In addition, the considered system, urban landscape, determines the needed scale, which is a consequence of small-scale heterogeneous urban characteristics.

The conceptual hierarchical framework is shown in Table 1 , specifying a selection of relevant indicators for the fundamental dimensions. Risk is split up into the components of equation 1 . The consistent systematization leads to a selection of indicators, in this case describing the example system, "urban area". The holistic approach aims at an integrative concept for involving various research communities in the conceptual framework. In this study Table 1 serves as the basic outline to identify capabilities and limitations of remote sensing data and methods to contribute to the approach.
3 The capabilities of remote sensing data and methods to contribute to the risk framework

The conceptual framework displayed in Table 1 establishes a basis for various research communities to identify their potential contributions. A consistent continuation of this study provides results which use remote sensing data and methods to contribute indicators to the proposed theoretical, conceptual framework. It is shown how various data types enable both the assessment of indicators related to the hazard and the assessment of indicators related to vulnerability. The test site for the study is the working-class district Zeytinburnu, located on the European side of the earthquake prone megacity Istanbul. The enormous risk for the megacity Istanbul is shown by the magnitude 7.4 earthquake which struck on 17 August 1999 in the Kocaeli province about 150 km southeast of Istanbul. The dimension of this past catastrophe is reflected in more than 18000 deaths, 49000 injured 16400 destroyed buildings and 60000 people homeless (Erdik, 2001).

For an adequate assessment of the values of these indicators contributing to the conceptual framework, high and medium spatial resolution optical satellite data (IKONOS and Landsat) as well as an interferometric Digital Elevation Model (DEM) based on X- and C-band data from the SRTM are used. IKONOS data feature a geometric quality of one 
meter panchromatic, four meter multispectral and one meter pan-sharpened imagery. Thus, these remote sensing data provide the ability to cover the small-scale and heterogeneous urban morphology. In addition, the use of data from Landsat satellites, available since 1972, enables on a lower geometric resolution of $15 \mathrm{~m}$ a temporal analysis of urban development. The DEM provides pixel spacing of $25 \mathrm{~m}$ and a height accuracy of about six meters. Figure 2 displays Ikonos imagery recorded in 2005 showing a spatially diverse and heterogeneous urban structure. The quarter is characterized by many different building types, built-up densities and structural patterns, all of which imply a diverse spatial distribution of vulnerability and risk.

Four different locations in the Zeytinburnu district are exemplarily displayed in Fig. 2 to show in the course of the analysis how different land cover and locations affect spatial patterns of vulnerability and risk. Location 1 is a multi-storey building in a dense residential area, located at the edge of the settlement near the coastline on low terrain. Similar characteristics apply for location 2, except for its location on higher terrain. Location 3 shows a 5-6 storey building typical for the building stock of Istanbul and located in the heart of Zeytinburnu. The area is characterized by narrow alleys, highly dense built-up structures and a block by block alignment. In comparison, location 4 is an open space, more precisely a vegetated public park.

\subsection{Hazards}

Due to missing ancillary earthquake data the spatial effect of an earthquake hazard is assumed to be constant for the whole test site Zeytinburnu. Using a Digital Elevation Model (DEM) from the SRTM a spatial distribution of possible areas for the occurrence of secondary threats is derived. The assessment of indicators - landslide and tsunami prone areas - influencing the spatial distribution and probability of the occurrence of earthquake after-effects is assessed.

The inclination of the slope is computed with a tangent equation taking neighbouring pixel height values into account. The result projects the spatial distribution of the steepness of slopes, which serve as one component to identify areas at high risk for landslides in the case of an earthquake. Of course, steepness is not solely decisive for the occurrence of landslides, but it does provide a spatial containment to possible areas. The height information in combination with the orientation of the slopes calculated from the DEM is used to approximately model affected areas in case a tsunami wave hits the urban coastline. The calculation is based on the normal coastline extracted from a land cover classification based on Ikonos data. Using assumed wave heights, the DEM allows a coarse identification of areas prone to a potential tsunami wave. Figure 3 displays the spatial distribution of areas at risk of secondary threats in the earthquake case for the district of Zeytinburnu.

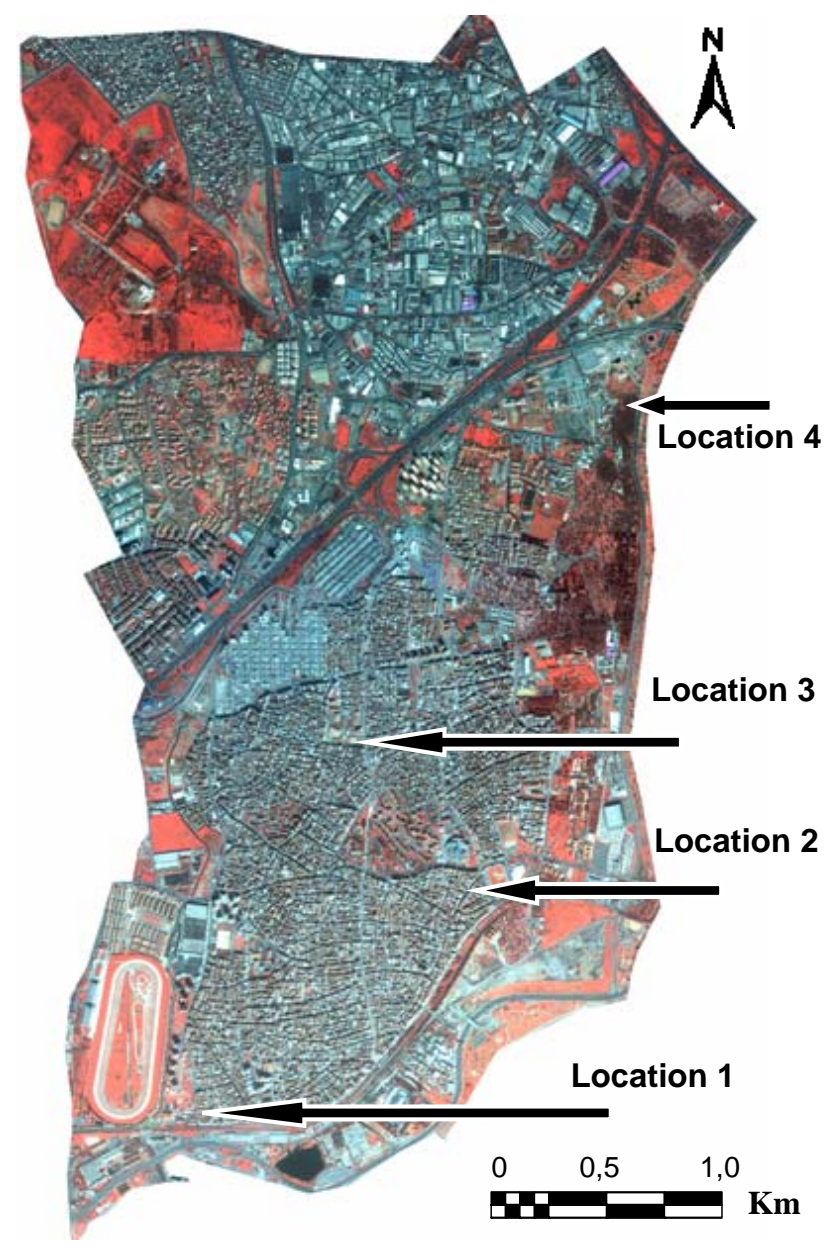

Fig. 2. IKONOS imagery from the test site, Zeytinburnu district in Istanbul, Turkey.

\subsection{Vulnerability}

Based on high resolution satellite data (Ikonos), the complex and heterogeneous urban landscape has been classified automatically using an object-oriented, fuzzy-based approach with accuracy higher than $84 \%$. The methodology has been presented using a hierarchical guideline utilizing spectral, shape and contextual image information (Taubenböck and Roth, 2007). Based on this land cover information, which provides seven basic classes - buildings, streets, grassland, trees/bushes, bare soil, shadows and water - analysis leads to indicators describing the physical and demographic component of the vulnerability framework (Table 1).

The spectral and structural characteristics of the data and the classification result are used to distinguish building characteristics, in particular the built-up density (Fig. 4) and the building height. The built-up density is based on a moving window approach taking the neighbourhood of the particular house into account (Taubenböck et al., 2006). The assessment of building heights is calculated using the 


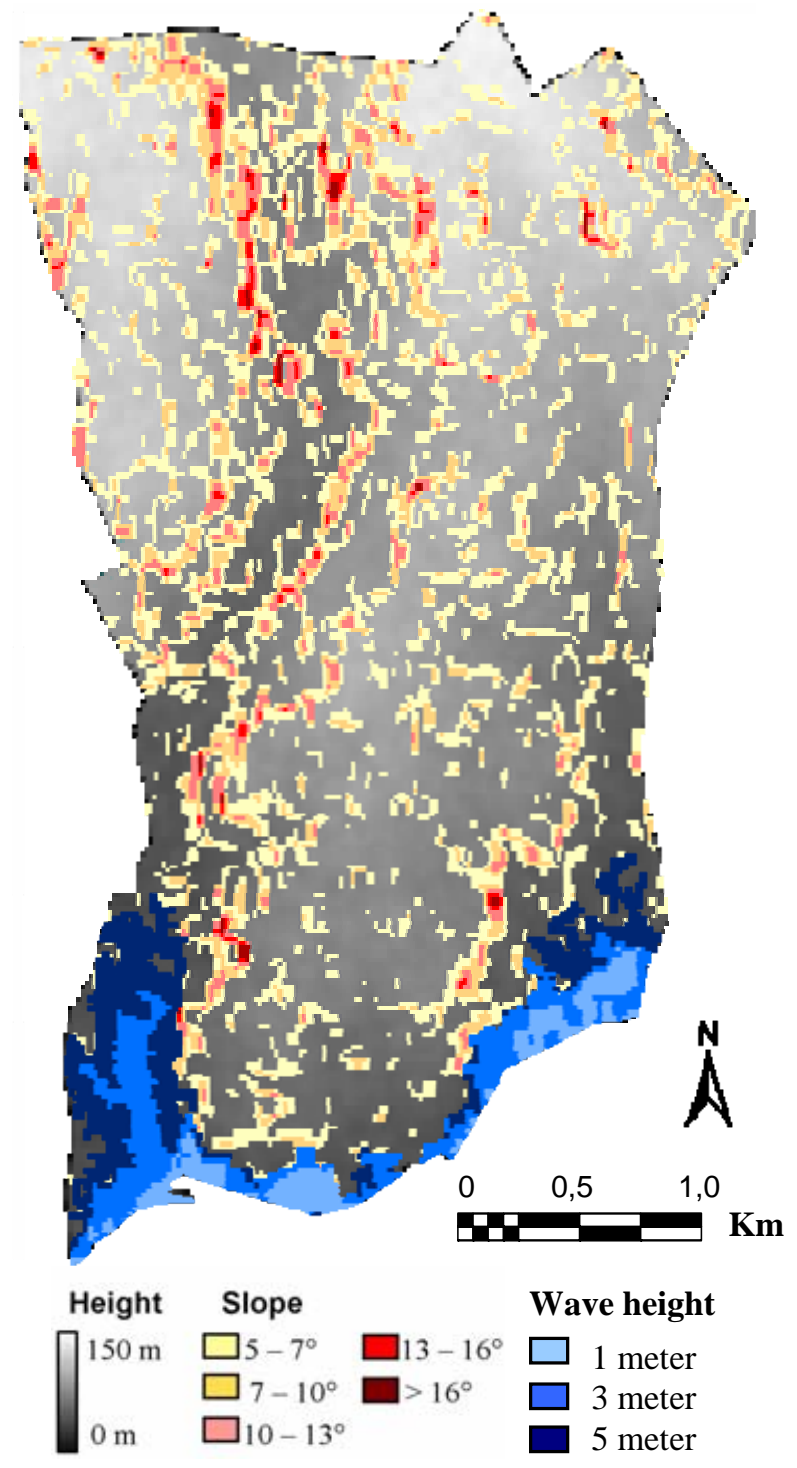

Fig. 3. Spatial distribution of potential secondary threats.

corresponding shadow lengths of houses. An interpolation method enables assessment of three height classes with accuracy higher than $90 \%$. The property of building roofs to have a brighter side facing the sun and a darker side turned away from the sun is used to derive gable roofs and, as the case may be, flat roofs. This information in combination with the size of the buildings and their location is used to assess the predominant usage - residential or commercial. In addition, using a temporal series of Landsat data, post-classification change detection enables the assessment of building ages as well as urbanization rates (Taubenböck, 2008). The street network extracted from the land-cover classification is used as the basis for analyzing accessibility based on distance functions (Fig. 4). Furthermore, the structural characteristics of the houses - building heights, building density and land use - allow an indirect assessment of the population distribution within the urban landscape with accuracies of around 90\% (Taubenböck et al., 2007). Using the assessment of the location of commercial and residential areas, even the dynamic spatial shift of the population as a function of the time of day is computed.

Figure 4 displays three vulnerability indicators in their spatial distribution. This illustrates the location-based interaction of various indicators influencing vulnerability and thus, risk. The indicator built-up density provides information on the spatial distribution and quantity of potentially endangered structures within the urban landscape. The indicator distance to inner city highway enables a geospatial assessment of accessibility. In addition the distance analysis to open spaces delivers insight into accessibility of areas of security. It also enables the assessment of potential areas for shelters. In terms of the time flow of the risk cycle these indicators regarding locations of and distances to infrastructure and open spaces, respectively, enable identification of highly vulnerable areas as well as coping capacity during and after the event. The population distribution is projected on the building mask spatially specified by the characteristics height, floor area and usage. It shows the number of endangered people in their spatial distribution. Here, the night-time population distribution shows low density in the large commercial areas in the northeast of the district, while during the day a shift to these areas takes place. Thus, the temporal dimension is also included in the assessment of vulnerability and risk, resulting in a dynamic spatial relocation of potentially affected people.

\subsection{Indexing to quantify risk relatively in its spatial distri- bution}

Vulnerability and risk are dynamic phenomena often in a continuous state of flux, as the various components that shape local conditions and the ability to cope are themselves dynamic (O'Brien et al., 2004). The reviewed research struggles to objectively find metrics for vulnerability. The translation of a complex set of heterogeneous indicators into a quantitative metric in many ways reduces its impact and hides its complexity (Alwang et al., 2001). But, quantitatively combining the available indicators aims at deeper insight into complex processes of interrelation, and thus it enables a general and more holistic view on vulnerability and risk than the isolated assessment of single indicators.

This study proposes a mathematical quantification that provides a standardized range making indicators comparable across time and location. This mathematical quantification of heterogeneous impact indicators enables approximation of the complexity of their interrelations. In order to analyse interactions of the various types of indicators derived from remote sensing data, an indexing system is proposed for a standardized classification of thematic information as 
a) Built-up density

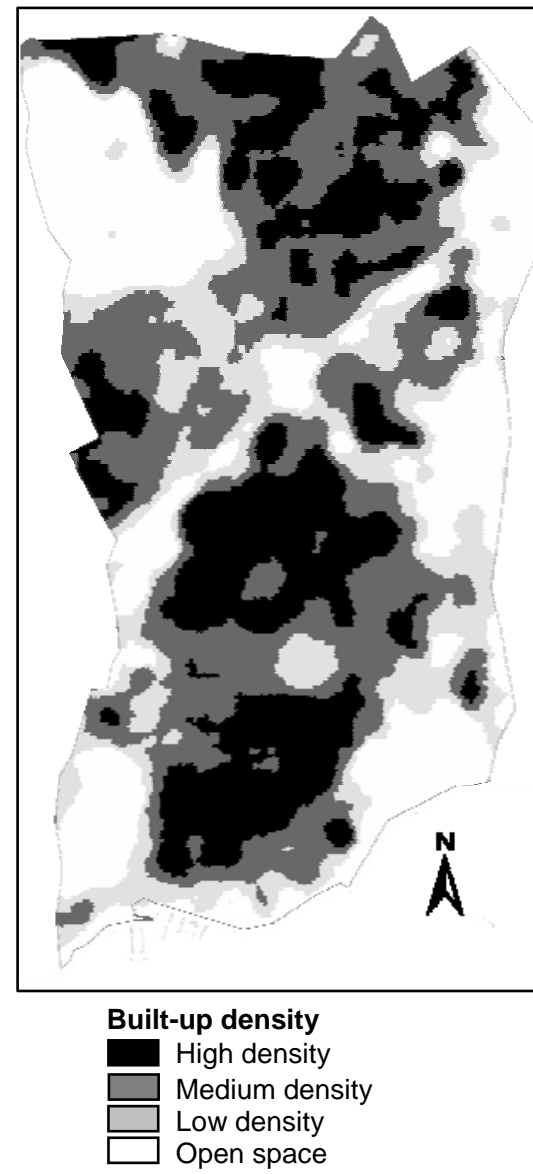

b) Distances

c) Night time population distribution

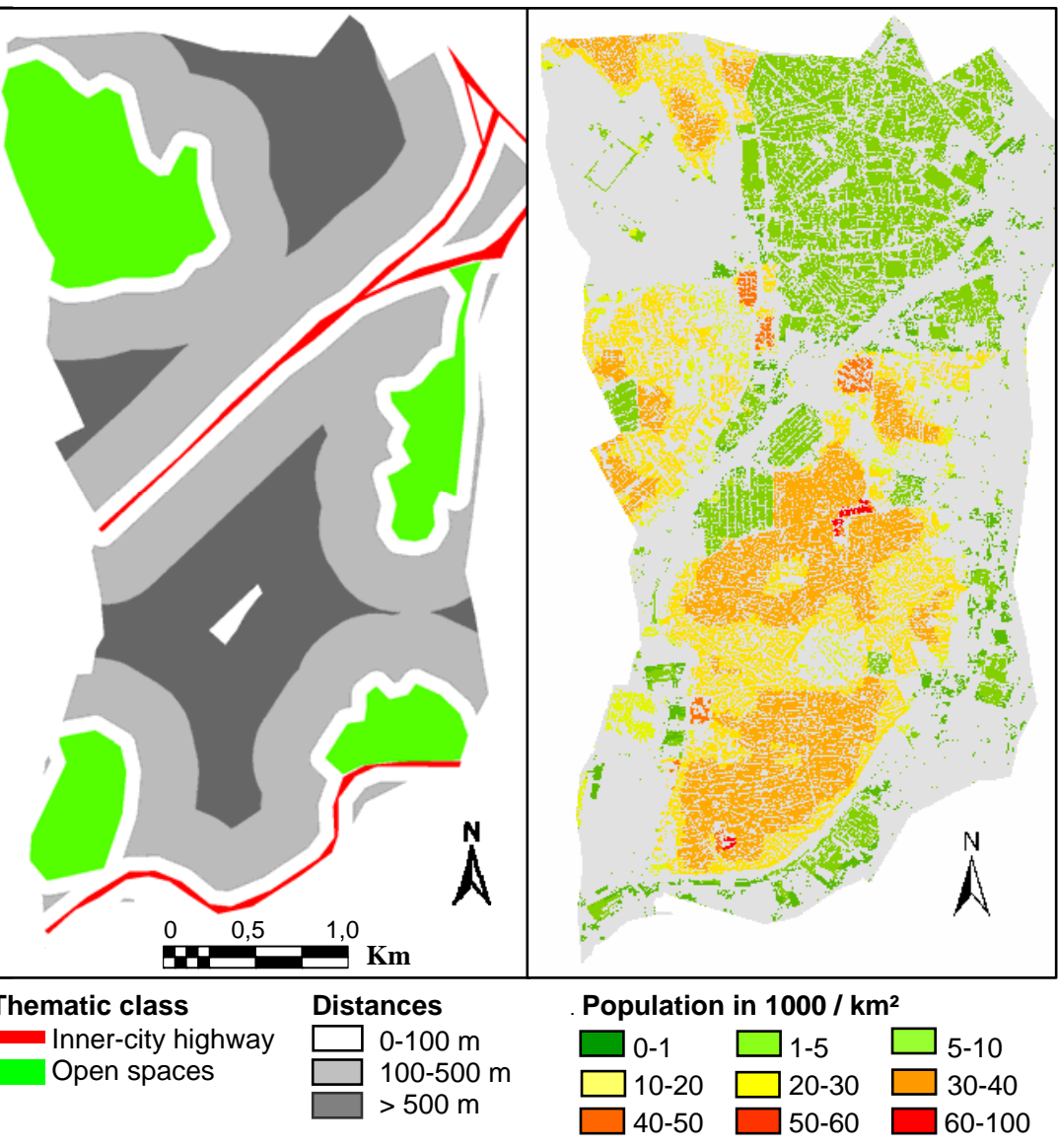

Fig. 4. Indicators contributing to the holistic concept of risk and vulnerability.

to vulnerability. The standardized scale enables the provided indicators to be combined.

In general the index system is expected to bring benefits by:

- Systemising and harmonising the presentation of risk information

- Providing comparative parameters for monitoring changes to evaluate the effects of policies

- Measuring key elements of vulnerability and risk and identifying their spatial distribution (Bollin et al., 2006).

In particular, the indexing aims at a holistic projection to identify interactions of the hazard and the diverse indicators describing vulnerability with spatial reference. In our case it enables embedding of very different types of spatial information influencing vulnerability and risk. Thus, different indicators like population or distance to highways can be incorporated in the same assessment to simulate interdependencies. For that purpose, the indexing converts values of the individual indicators into a standardized range. The parameterization should be based on historical or empirical information with respect to the considered event. If these data sets are missing, it is proposed to parameterize the information of the various derived indicators using a theoretical (continuous) function, based on expertise.

Due to missing historical information the parameterization in this study uses S-functions to convert thematic information in index values. The advantage of $\mathrm{S}$-functions converging to the minima $(0=$ not vulnerable) or the maxima $(1=100 \%$ vulnerable) of the index enables differentiation of even extreme values. In addition, the requirement for the S-shaped function is a low gradient, in order to achieve little index differences for similar thematic values. The inflexion point of the curve (Index value 0.5 ) reflects a thematic value of the particular indicator considered as critical with respect to vulnerability. The mathematic function for it is displayed, using the variable "a" to control the gradient of the curve.

$$
P(t)=\frac{1}{1+e^{(a \times(-t))}}
$$



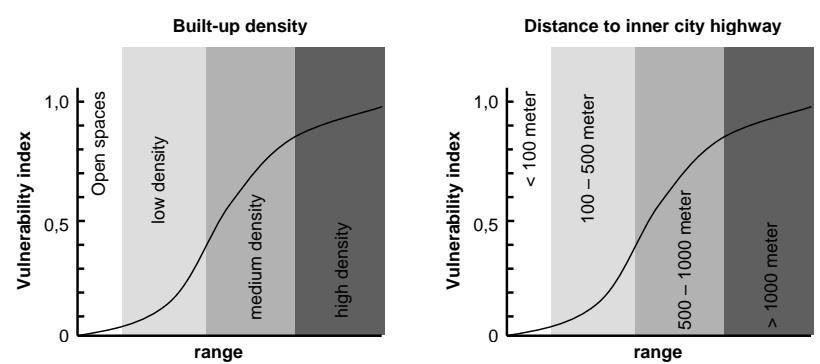

Fig. 5. Parameterization of vulnerability indicators on a uniform scale.

Consequently, using the normalization of vulnerability indexes, opposed areas can still be compared based on the same scale.

Below, the parameterization of example indicators on a standardized index translating thematic values into the vulnerability index from 0 to 1 is displayed. The gradient is suggested to be low to achieve significantly different vulnerability indices for different thematic values. The indicator built-up density provides information on the spatial distribution and its quantity of potentially endangered structures within the urban landscape. The indicator distance to inner city highway enables a geospatial assessment of accessibilities. Figure 5 displays an S-function based on equation 3 attributing index values for the particular range value of the individual indicator.

The indexing allows the combining of different kinds of thematic information resulting in a synergistic surplus value. An open space at a distance of $500 \mathrm{~m}$ to the inner city highway offers with a high probability a higher accessibility than does a highly dense built-up area at the same distance. The combination is therefore essential, to assess risk from a more holistic perspective. On the lines of these two examples, the indicators derived from remote sensing data and methods are converted to the index as well.

The indiscriminate use of indicators for measuring vulnerability and risk - pick any that seem to be relevant and/or available - must be avoided; rather, it is important to define and develop at least an implicit model to serve as a systematic basis for indicator development and selection (Downing, 2004). Table 1 shows a holistic approach specifying a wide selection of potential indicators which are at times partly redundant. To develop scientifically sound indicators it is necessary to formulate goals that serve as a starting point for the identification of relevant indicators (Birkmann, 2006a). Consequently, using the two example indicators from Fig. 5, the indicandum describes physical vulnerability with spatial information at the same scale. An inductive method is implemented, using the available indicators derived from remote sensing without consideration of missing indicators of the holistic approach. This enables the identification of the capabilities of remote sensing to contribute to the vulnerability and risk assessment.

The procedure of indexing has to be arranged regarding the specific hazard, and a weighting has to be found and applied (Bollin et al., 2006). The highest risk for the population in case of an earthquake emanates from buildings (Bakir et al., 2002). Based on this premise, a need emerges for giving the highest weighting to the indicators buildings and population. In our case the buildings $\left(L_{h}\right)$ derived in the land cover classification and the population $\left(P_{n} ; P_{d}\right)$ are weighted fourfold. Thus, the risk index for an area without houses cannot be higher than an area covered by a house.

Further indicators derived from remote sensing data (see Figs. 4 and 5) are weighted equally due to missing empirical information on the effects. The inclusion of indicators in general requires non-redundancy. But as an example shows, the built-up density $\left(B_{d}\right)$ does show redundancy to the indicator houses $\left(L_{h}\right)$. However, in addition it also specifies the information needed to achieve surplus value. The combination reflects a higher vulnerability for a house in a highly dense built-up area compared to a house standing in a low density built-up area. Thus, the combination of both indicators allows for the integration of physical aspects like higher probability of bouncing effects for neighbouring houses in case of an earthquake, or higher probability for lower accessibility in highly dense built-up areas. The physical aspects can even be specified using information about the height of the building $\left(B_{h}\right)$, the age $\left(B_{a}\right)$ or the urbanization rate $(U)$ of an area. The indicators describing distances, "Distance to infrastructure $\left(D_{i}\right)$ " and "Distance to open spaces $\left(D_{o}\right)$ " enable assessment of the accessibility of areas, carrying capacities of the street network, the chances to reach safe areas in a certain amount of time, and the potential for campsites after an event. They thus specify physical vulnerability before an event as well as coping capacity during and after the event. The demographic indicators (night- and daytime population density) enable inclusion of the dimension "time of day" in the assessment process. Vulnerability is manifest in specific places at specific times. It allows for the dynamic spatial shift of the population distribution in the course of a day and thus, a spatial shift of vulnerability and risk. Equation 4 shows the assessment of vulnerability using indicators derived from remote sensing data $\left(V_{R S}\right)$ using aspects of the framework in Table 1.

$$
\begin{aligned}
& V_{R S}=\frac{1}{n} \times\left(w_{1} L_{h}+w_{2} B_{d}+w_{3} B_{h}+w_{4} D_{i}+U\right. \\
& \left.w_{5} D_{o}+w_{6}+w_{7} B_{a}+w_{8} P_{d / n}\right) \\
& n=\text { number of indicators and their weights } \\
& \quad w_{1-8}=\text { individual weighting factor for each indicator }
\end{aligned}
$$

In the following, indicators describing the spatial distribution of the earthquake hazard $(E)$ and its potential aftereffects like landslides $(S)$ and tsunami areas $(T)$ are calculated. Due to missing data on the spatial distribution of the 
earthquake stress, this study assumes a constant earthquake effect. The hazard stress is differentiated using remote sensing results $\left(H_{R S}\right)$ approximating potentially occurring aftereffects in their spatial distribution.

$$
H_{R S}=\frac{1}{n} \times\left(w_{1} E+w_{2} S+w_{3} T\right)
$$

$n=$ number of indicators and their weights

$$
w_{1-3}=\text { individual weighting factor for each indicator }
$$

In the following the inductively calculated vulnerability and hazard index based on products derived from remote sensing data are combined based on the interrelation suggested in Eq. 1. Thus, the risk index $\left(R_{R S}\right)$ results from indicators representing the abstract terms of Eq. 1. The mathematical operation of Eq. 1 symbolizes the dependencies of both components, but is here changed to addition to gain results between 0 and 1 instead of minimizing the values using multiplication.

$$
R_{R S}=\frac{1}{2} \times(V+H)
$$

Table 2 lists the indicators derived from remote sensing data to analyse the spatial distribution of vulnerability as well as of hazards. The available indicators show in comparison with the framework of Table 1 the capability of remote sensing to contribute aspects to the general holistic idea. It shows a clearly arranged listing of available indicators and displays their relative vulnerability to each other. This method enables a comparison of locations based on these individual indicators, identification of risk-determining indicators, and eventually assessment of risk based on the available aspects of the holistic concept. The four sample locations have been presented in Fig. 2.

Recapitulating, the performed indicators are aspects of the risk framework of Table 1, and thus enable identification of the capabilities of remote sensing, but also its limitations. The comparison of provided indicators and suggested indicators in Table 1 shows the potential of remote sensing contributions. The assessment using derived remote sensing products clearly highlights the capabilities for physical and demographic indicators describing vulnerability as well as the spatial distribution of aspects of after-effects. The limitations of remote sensing to contribute to the comprehensive framework of vulnerability and risk are shown in the missing aspects of social, economic and political indicators.

The four different locations displayed in Fig. 2 and used in Table 2 enable a location-based analysis of risk and an identification of key indicators. Basically, locations 1, 2 and 3 show high vulnerability and risk due the fact that the highest vulnerability for the population emanates from structures. Comparing the three endangered locations, location 3 displays the highest vulnerability, with the key indicators high
Table 2. Combination of vulnerability and hazard defining indicators for four example locations.

\begin{tabular}{|l|c|c|c|c|}
\hline Vulnerability indicator & Location 1 & Location 2 & Location 3 & Location 4 \\
\hline \hline Land cover $\left(\mathrm{L}_{\mathrm{h}}\right)$ & 1.00 & 1.00 & 1.00 & 0.00 \\
\hline Built-up density $\left(\mathrm{B}_{\mathrm{d}}\right)$ & 0.57 & 0.64 & 0.87 & 0.00 \\
\hline Building height $\left(\mathrm{B}_{\mathrm{h}}\right)$ & 0.25 & 0.25 & 0.50 & 0.00 \\
\hline Distance to infrastructure $\left(\mathrm{D}_{\mathrm{i}}\right)$ & 0.28 & 0.34 & 0.81 & 0.18 \\
\hline Distance to open spaces $\left(\mathrm{D}_{\mathrm{o}}\right)$ & 0.15 & 0.29 & 0.77 & 0.00 \\
\hline Urbanization rates $(\mathrm{U})$ & 0.10 & 0.50 & 0.10 & 0.00 \\
\hline Building age ( $\left.\mathrm{B}_{\mathrm{a}}\right)$ & 0.75 & 0.25 & 0.75 & 0.00 \\
\hline Population density (night) $\left(\mathrm{P}_{\mathrm{n}}\right)$ & 0.16 & 0.22 & 0.44 & 0.00 \\
\hline Population density (day) $\left(\mathrm{P}_{\mathrm{d}}\right)$ & 0.44 & 0.54 & 0.85 & 0.00 \\
\hline \hline Vulnerability index (night) & $\mathbf{0 . 4 8}$ & $\mathbf{0 . 5 1}$ & $\mathbf{0 . 6 8}$ & $\mathbf{0 . 0 1}$ \\
\hline \hline Vulnerability index (day) & $\mathbf{0 . 5 6}$ & $\mathbf{0 . 6 0}$ & 0.80 & $\mathbf{0 . 0 1}$ \\
\hline \hline Slope (S) & 0.65 & 0.43 & 0.05 & 0.15 \\
\hline Tsunami exposure (T) & 0.82 & 0.00 & 0.01 & 0.00 \\
\hline \hline Risk index (day) & $\mathbf{0 . 5 1}$ & $\mathbf{0 . 4 6}$ & $\mathbf{0 . 6 0}$ & $\mathbf{0 . 0 2}$ \\
\hline \hline Risk index (night) & $\mathbf{0 . 5 8}$ & $\mathbf{0 . 5 5}$ & $\mathbf{0 . 7 0}$ & $\mathbf{0 . 0 2}$ \\
\hline \hline Vulnerability: $\square$ very high \\
\hline
\end{tabular}

built-up density, low accessibility, and high population density. Thus, the location in the heart of the district with narrow alleys, in a highly dense built-up area leads to higher vulnerability compared with locations 1 and 2, which show similar building characteristics, but a better connection to infrastructure or open spaces. Locations 1 and 2 show more or less the same building characteristics as well as the same relative location to secure areas or infrastructure, which results in a very similar vulnerability index. In comparison, location 4 emerges as a low risk open space area qualifying as a rescue area in case of an earthquake.

The course of the day influences the spatial distribution of vulnerability and risk. Zeytinburnu is a working-class district featuring a higher population density during daytime. This is reflected in the higher vulnerability index of the example locations during daytime. The time dimension not only influences the vulnerability and risk index, but also shifts the spatial distribution of risk from commercial to residential areas and vice versa.

The combination of hazard indicators with vulnerability indicators shows an interesting effect. While location 2 results in a higher vulnerability index compared to location 1 , the high hazard index of location 1 - being prone to landslides and tsunami - results in a contrary risk index for both locations. This shows the importance of a holistic integrated approach to identify key indicators, and thus, derive types and locations of preventive measures.

Referring to these results the simulated mathematical combination of various aspects of risk and vulnerability results in deeper insight of processes and their interaction and thus adds up to surplus value. At the same time, the combination of very different indicators contains an artificial simulation of interdependencies and can only approach reality. 
In addition the limited amount of available indicators using solely remote sensing data can lead to misinterpretation. As example, a building in a highly dense built-up area with low accessibility may be constructed very stable which would reduce its vulnerability and risk in comparison to a building in an opposite area that may be constructed unstable. Thus, the vulnerability and risk of the latter may be higher although differently indicated in our assessment. Hence, we sum up that remote sensing can only illuminate a part of vulnerability and risk, and an assessment must consider potential impacts of not available indicators.

The results present the spatial distribution of risk within the complex urban landscape as well as changes depending on the time of day. Using this inductive method the risk assessment shows aspects of the holistic framework based on remote sensing. The combination of indicators using indexing enables the identification of "where" and "what type" of preventive measures is needed.

\section{Conclusions}

The many kinds of vulnerability and risks can indeed only be understood with sophisticated information management systems. This study focuses on a holistic approach for a conceptual framework of hazards, vulnerability and risks. The conclusion addresses the three questions defined earlier in the introduction. How can risk, vulnerability and hazards be conceptualized in a general and transferable framework? What can remote sensing data and methods contribute toward assessing risk and vulnerability in their spatial distribution? How can the abstract terms in the framework be sampled to quantifiable indicators?

The presented meta-framework aims at a consistent concept applicable to provide complementary quantitative and qualitative insights into outcomes and perceptions of risks. Depending on the considered hazard, system, time and scale-applicable indicators specify the general abstract metaframework. The hierarchical structure systematizes the abstract terms to measurable indicators. Along the holistic approach, it becomes evident that the interactions in the case of a disastrous event are very complex. Hence, the approach to assess vulnerability and risk must focus on complementary multidisciplinary analysis. The circumstantial listing of potential indicators aims at an identification of possible contributions of various research communities, but also to identify their limitations.

Following the outline of this study, the capabilities and limitations of remote sensing data, methods and resulting products have been presented and discussed. Remote sensing allows analysis of indicators regarding exposure, susceptibility and coping. Based on the example system "urban landscape", indicators derived from various remote sensing data are displayed. Products derived from high and medium resolution optical satellite data as well as radar data are, for example, land cover, built-up densities, accessibility, population density, building age, urbanization rates or even the approximation of the spatial distribution of after-effects like landslides or tsunami prone areas in the case of an earthquake. Using an inductive method, available indicators are combined with an indexing approach to assess aspects of risk and identify key indicators as well as their spatial distribution. Indexing simplifies the complex problem of multiindicator interactions, but enables modeling the impact of the various aspects. It is useful to prioritize certain indicators based on historic observations or expert knowledge, but weighting always contains subjectivity and to some degree uncertainty. The result emphasizes the capabilities of remote sensing to assess aspects of physical and demographic vulnerability as well as aspects defining the spatial distribution of after-effects in case of an earthquake. Limitations of remote sensing to date are how to derive reliable values on socio-economic and political components.

The presented capabilities and limitations of remote sensing with respect to a certain threat and a certain system also show potential for different scenarios. Whether the threat is a volcanic eruption, a flood, or whatever threatens people, man-made structures or natural landscapes, the structural characteristics of the system, the locations and the population distribution will have importance in mapping spatial vulnerability and risk patterns.

Concluding, it becomes evident that there is no panacea for risk management and decision-making. In fact, this approach supports the identification of risk and its spatial distribution, but to have a bearing on reality: it must lead to precise supporting measures. So, in reference to the quotation from Peduzzi (2006) in the introduction, the analysis of where to implement supporting measures is supposed to become a driver to raise the awareness of the people at risk and of the political decision makers of the need to invest in prevention.

Edited by: T. Glade

Reviewed by: three anonymous referees

\section{References}

ADPC (ASIAN DISASTER PREPAREDNESS CENTRE): The Role of Local Institutions in Reducing Vulnerability to Recurrent Natural Disasters and in Sustainable Livelihoods Development in High Risk Areas, Report submitted to FAO, source, ftp://ftp.fao.org/docrep/nonfao/ad695e/ad695e00.pdf, 2003.

Adger, W. N.: Vulnerability, Glob. Environ. Change, 16, 268-281, 2006.

Alwang, J., Siegel, P. B., and Jorgensen, S. L.: Vulnerability: A view from different disciplines, Discussion Paper Series No. 0115. Social Protection Unit, World Bank, Washington D.C., 2001.

Bakir, P. and Boduroglu, H.: Earthquake Risk and Hazard Mitigation in Turkey, Earthquake Spectra, 18(3), 427-447, 2002.

Birkmann, J.: Measuring vulnerability to promote disaster-resilient societies: Conceptual frameworks and definitions, in: Measuring 
Vulnerability to Natural hazards - Towards Disaster Resilient Societies, edited by: Birkmann, J., New York, United Nations University, 9-54, 2006a.

Birkmann, J.: Indicators and criteria for measuring vulnerability: Theoretical bases and requirements, in: Measuring Vulnerability to Natural hazards - Towards Disaster Resilient Societies, edited by: Birkmann, J., New York, United Nations University, 55-77, $2006 \mathrm{~b}$

Blaikie, P., Cannon, T., Davis, I., and Wisner, B.: At Risk: Natural Hazards, People's Vulnerability and Disasters, London: Routledge, 1994.

Bollin, C. and Hidajat, R.: Community-based risk index: Pilot implementation in Indonesia, in: Measuring Vulnerability to Natural hazards - Towards Disaster Resilient Societies, New York, United Nations University, edited by: Birkmann, J., 524, 2006.

Bohle H.-G.: Vulnerability and Criticality: Perspectves from Social Geography, IHDP Update 2/2001, Newsletter of the International Human Dimensions Programme on Global Environmental Change, 1-7, 2001.

Briuglio, L.: Methodological and Practical Considerations for Constructing Socio-Economic Indicators to Evaluate Disaster Risk, Institute of Environmental Studies, University of Columbia, Manizalez, Colombia, Programme on Information and Indicators for Risk Management, IADB-ECLAC-IDEA, 2003.

Brooks, N.: Vulnerability, Risk and Adaption: A conceptual framework, Working Paper 38, Tyndall Centre for Climate Change Research, Norwhich, UK, 1-20, 2003.

Cardona, O. D.: The need of rethinking the concepts of vulnerability and risk from a holistic perspective: A necessary review and criticism for effective risk management, in: Bankoff, G., Frerks, G., Hilhorst, D., Mapping Vulnerability: Disasters, Development and People, Earthscan, London (Chapter 3), 2003.

Chapmann, D.: Natural Hazards, Oxford: Oxford University Press, 1994.

Cutter, S. L.: Vulnerability to environmental hazards, Progress in Human Geography 20 (1996), 529-539, 1996.

Downing, T.: What have we learned regarding a vulnerability science?, in: Science in Support of Adapation to Climate Change, Recommondations for an Adaptation Science Agenda and a Collection of Papers Presented at a Side Event of the 10th session of the Conference of the Parties to the United States Framework Convention on Climate Change, Buenos Aires, 7 December 2004, 18-21, 2004.

Dkkv - Deutsches Komitee Katastrophenvorsorge e. V.: Lessons learned - Hochwasservorsorge in Deutschland: Kurzfassung für die Versicherungswirtschaft, http://www.dkkv.org/DE/ publications/schriftenreihe.asp?h=5, 2002.

Erdik, M.: Report on 1999 Kocaeli and Düzce (Turkey) earthquakes, in: Structural control for civil and infrastructure engineering, edited by: Casciati, F. and Magonette, G., World Scientific, 2001.

Füssel, H. M.: Vulnerability: A generally applicable conceptual framework for climate change research, Glob. Environ. Change, 17(2), 155-167, 2007.

Füssel, H. M.: Vulnerability in climate change research: A comprehensive conceptual framework, University of California, International and Area Studies - Breslauer Symposium No. 6, 2005.

Gallopin, G.: Indicators and their use: Information and decisionmaking, Part One: Introduction, in: Sustainability Indicators:
Report of the Project on Indicators of Sustainable Development, SCOPE Scientific Committee on Probems of the Environment, edited by: Moldan, M. and Billharz, S., New York: John Wiley, 1997.

Kasperson, R. E., Dow, K., Archer, E. Caceres, D., Downing, T., Elmqvist, T., Eriksen, S., Folke, C., Han, G., Iyengar, K., Vogel, C., Wilson, K., and Ziervogel, G.: Vulnerable people and places, in: Ecosystems and Human Well-being: current state and trends, Hassan, R., Scholes, R., Ash, N., 1. Island Press. Washington D. C., 143-164, 2005.

Kasperson, J. X. and Kasperson, R. E.: International workshop on vulnerability and global environmental change, SEI Risk and Vulnerability Programme Report 2001-01, Stockholm Environment Institute, Stockholm, Sweden, 2001.

Liverman, D. M.: Vulnerability to global environmental change, in: Understanding Global Environmental Change: The Contributions of Risk Analysis and Management, edited by: Kasperson, R. E., Dow, K., Golding, D., and Kasperson, J. X., Clark University, Worcester, MA (1990), 27-44 (Chapter 26), 1990.

O’Brien K. L., Leichenko, R. M., Kelkarc, U., Venemad, H., Aandahl, G., Tomkins, H., Javed, A., Bhadwal, S., Barg, S. Nygaard, L., West, J.: Mapping vulnerability to multiple stressors: climate change and globalization in India, Global Environmental Change 14, 303-313, 2004.

Peduzzi P.: The Disaster Risk Index: Overview of a quantitative approach, in: Measuring Vulnerability to Natural hazards - Towards Disaster Resilient Societies,edited by: Birkmann, J., New York, United Nations University, 524, 2006.

Pelling, M.: The Vulnerability of Cities - Natural Disasters and Social Resilience, 212, Earthscan Publications Ltd., ISBN-185383830-6, London, 2003.

Rashed, T. and Weeks, J.: Assessing vulnerability to earthquake hazards through spatial multicriteria analysis of urban areas, International Journal of Geographical Information Science, 17(6), 547-576, 2003.

Schneiderbauer S. and Ehrlich, D.: Social levels and hazard (in)dependence in determining vulnerability, in: Measuring Vulnerability to Natural hazards - Towards Disaster Resilient Societies edited by: Birkmann, J., New York, United Nations University, 78-102, 2006.

Schneiderbauer, S.: Risk and Vulnerability to Natural Disasters - from Broad View to Focused Perspective, PhD-Thesis, Freie Universität Berlin, pp. 121, available at: http://www.diss. fu-berlin.de/2007/498/indexe.html, 2007.

Taubenböck, H., Roth, A., and Dech, S.: Linking structural urban characteristics derived from high resolution satellite data to population distribution, in: Urban and Regional Data Management, COORS, RUMOR, edited by: Fendel, E. and Zlatanova, S., Taylor \& Francis Group, London, ISBN978-0-415-44059-2, 35-45, 2007.

Taubenböck, H., Roth, A.: A transferable and stable classification approach in various urban areas and various high resolution sensors, in: Urban Remote Sensing Joint Event, Paris, France, 7, 2007.

Taubenböck, H., Habermeyer, M., Roth, A. and Dech, S.: Automated allocation of highly-structured urban areas in homogeneous zones from remote sensing data by Savitzky-Golay Filtering and curve sketching, IEEE Geoscience and Remote Sensing Letters, 3(4), 532-536, ISSN 1545-598X, 2006. 
Taubenböck, H.: Vulnerabilitätsabschätzung der erdbebengefährdeten Megacity Istanbul mit Methoden der Fernerkundung, PhD Thesis, University of Würzburg, p. 174, (To be published), 2008.

Timmermann, P.: Vulnerability, Resilience and the Collapse of Society, No. 1 in Environmental Monograph, Toronto: Institute for Environmental Studies, University of Toronto, 1981.

Turner, B. L., Kasperson, R. E., Matson, P. A., McCarthy, J. J., Corell, R. W., Christensen, L., Eckley, N., Kasperson, J. X., Luers, A., Martello, M. L., Polsky, , C., Pulsipher, A., and Schiller, A.: A framework for vulnerability analysis in sustainability science, Proceedings of the National Academy of Science (USA), 100(14), 8074-8079, 2003.

Unesco: Annual Summary of Information on Natural Disasters, Paris, Unesco, 1973.

United Nations: Mitigating Natural Disasters: Phenomena, Effects, and Options: a Manual for Policy Makers and Planners, New York: UNDRO (United Nations Disaster Relief Organization), 1991.
United Nations Development Programme (UNDP): Reducing Disaster Risk - A challenge for development - A Global Report, ISBN 92-1-126160-0, New York, USA, 2004.

United Nations/ISDR (International Strategy for Disaster Reduction): Living with Risk: A global Review of Disaster Reduction Initiatives, United Nations International Strategy for disaster Reduction, Geneva, Switzerland: UN Publications, 2004.

Villagran de Leon, J. C.: Vulnerability - A conceptual and methodological review, in: SOURCE "Studies Of the University: Research Council Education" Publication Series of UNU-EHS, No.4/2006, 2006.

White, P., Pelling, M., Sen, K., Seddon, D., Russell, S., and Few, R.: Disaster Risk Reduction. A Development Concern, DFID, 2005.

Wisner, B., Blaikie, T., Cannon, T, and Davis, I.: At risk: Natural hazards, people's vulnerability and disasters, London, 2004. 